\title{
Racial Disparity Trends in Children's Dental Visits: US National Health Interview Survey, 1964-2010
}

WHAT'S KNOWN ON THIS SUBJECT: Various studies have documented marked racial/ethnic disparities in children's receipt of dental services at single time points or brief periods.

WHAT THIS STUDY ADDS: This study reveals significant improvements in children's receipt of dental care overall, as well as a dramatic narrowing of African American/white disparities in children's receipt of dental services over the last 40 years in the United States.
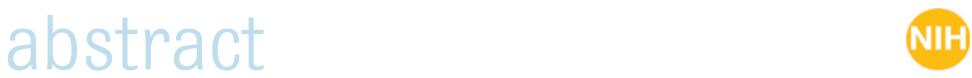

BACKGROUND AND OBJECTIVE: Research that has repeatedly documented marked racial/ethnic disparities in US children's receipt of dental care at single time points or brief periods has lacked a historical policy perspective, which provides insight into how these disparities have evolved over time. Our objective was to examine the impact of national health policies on African American and white children's receipt of dental care from 1964 to 2010.

METHODS: We analyzed data on race and dental care utilization for children aged 2 to 17 years from the 1964, 1976, 1989, 1999, and 2010 National Health Interview Survey. Dependent variables were as follows: child's receipt of a dental visit in the previous 12 months and child's history of never having had a dental visit. Primary independent variable was race (African American/white). We calculated sample prevalences, and $\chi^{2}$ tests compared African American/white prevalences by year. We age-standardized estimates to the 2000 US Census.

RESULTS: The percentage of African American and white children in the United States without a dental visit in the previous 12 months declined significantly from $52.4 \%$ in 1964 to $21.7 \%$ in 2010 , whereas the percentage of children who had never had a dental visit declined significantly $(P<.01)$ from $33.6 \%$ to $10.6 \%$. Pronounced African American/white disparities in children's dental utilization rates, whereas large and statistically significant in 1964, attenuated and became nonsignificant by 2010 .

CONCLUSIONS: We demonstrate a dramatic narrowing of African American/white disparities in 2 measures of children's receipt of dental services from 1964 to 2010. Yet, much more needs to be done before persistent racial disparities in children's oral health status are eliminated. Pediatrics 2012;130:306-314
AUTHORS: Inyang A. Isong, MD, MPH, ${ }^{a}$ Mah-J Soobader, $\mathrm{PhD},{ }^{\mathrm{b}}$ Susan A. Fisher-Owens, MD, MPH, ${ }^{\mathrm{C}}$ Jane A. Weintraub, DDS, MPH, ${ }^{d}$ Stuart A. Gansky, DrPH, ${ }^{\text {e Larry J. }}$ Platt, MD, and Paul W. Newacheck, DrPH ${ }^{c, f}$

aMassGeneral Hospital Center for Child and Adolescent Health Research and Policy, Harvard Medical School, Boston, Massachusetts; ' StatWorks, Boston, Massachusetts; ${ }^{\circ}$ Department of Pediatrics and ${ }^{f}$ Philip R. Lee Institute for Health Policy, School of Medicine, University of California, San Francisco, California, 'The University of North Carolina at Chapel Hill School of Dentistry, Chapel Hill, North Carolina; and ${ }^{\mathrm{C} C e n t e r}$ to Address Disparities in Children's Oral Health, School of Dentistry, University of California, San Francisco, California

KEY WORDS

children, racial disparities, dental care, NHIS

\section{ABBREVIATIONS}

aOR - adjusted odds ratio

CHIP_Children's Health Insurance Program

$\mathrm{Cl}$-confidence interval

EPSDT—Early Periodic Screening, Diagnosis, and Treatment

FPL-federal poverty level

MEPS—Medical Expenditure Panel Survey

NHIS-National Health Interview Survey

$O R$ - odds ratio

PB-Peters-Belson

SES-socioeconomic status

Drs Isong, Soobader, Fisher-0wens, Weintraub, Gansky, Platt, and Newacheck are responsible for the reported research. Each author participated in the conceptualization and design, interpretation of data, drafting and revising of the article, and has approved the article as submitted. In addition, Drs Soobader and Isong were responsible for conducting analyses.

Human Participant Protection: No human subjects were involved in this study.

www.pediatrics.org/cgi/doi/10.1542/peds.2011-0838

doi:10.1542/peds.2011-0838

Accepted for publication Apr 20, 2012

Address correspondence to Inyang A. Isong, MD, MPH, SM, MassGeneral Hospital Center for Child and Adolescent Health Research and Policy, 15th Floor, C100, 100 Cambridge St, Boston, MA 02114. E-mail: iisong@partners.org

PEDIATRICS (ISSN Numbers: Print, 0031-4005; Online, 1098-4275). Copyright (C) 2012 by the American Academy of Pediatrics FINANCIAL DISCLOSURE: The authors have indicated they have no financial relationships relevant to this article to disclose FUNDING: Supported by an award (R21 DE018523-02) from the National Institute of Dental and Craniofacial Research. Dr Isong's work was supported by a National Research Service Award (T32 HP10018) from the Health Resources and Services Administration, Department of Health and Human Services. Funded by the National Institutes of Health $(\mathrm{NIH})$ 
Dental care has historically been the leading unmet health care need among children in the United States, particularly among minority and low income children. ${ }^{1}$ Over the last half century, large-scale social policies have been directed at minorities and other disadvantaged groups in the United States that could have influenced their oral health outcomes. As part of America's War on Poverty and Great Society programs of the 1960s, several national health policies were implemented to increase access to care among lowand moderate-income groups. Key among these was the creation and subsequent expansions of Medicaid, ${ }^{2}$ enacted in 1965 to provide medical assistance for groups of categorically eligible needy individuals. ${ }^{3}$ The Early Periodic Screening, Diagnosis, and Treatment (EPSDT) program ${ }^{4}$ under Medicaid in 1967 expanded coverage for dental diagnostic screening and treatment services for all Medicaid-enrolled children. The Children's Health Insurance Program (CHIP) ${ }^{5}$ was added in 1997 to address coverage gaps among lowand moderate-income children not poor enough to qualify for Medicaid. Other important large-scale federal initiatives potentially impacting access to dental care include establishing community health centers in 1965 to increase access to health and social services among poor and medically underserved communities, passing the Civil Rights Act in 1964, Head-Start and Early Head-Start, and the Healthy People national health care objectives.

Although many federal programs were designed partly to reduce health care disparities, ${ }^{6}$ the enactment of Medicaid along with its subsequent expansions and the enactment of CHIP played central roles in expanding access to dental care. In both of these programs, children's oral health needs received special consideration. Unlike for adults, Medicaid mandates that states provide dental care to children, and EPSDT requires that states do not limit medically necessary dental care. Dental care is now covered under the Children's Health Insurance Program Reauthorization Act in all states ${ }^{7}$; even before dental coverage became mandatory in 2009, virtually all states covered at least basic dental services. $^{8}$

A few studies have examined trends in children's access to dental care and disparities in receiving dental services over time and how this relates to public health insurance programs. The authors of 1 study evaluated the impact of Medicaid and CHIP expansions on income disparities in children's dental service utilization between 1983 and 2001-2002. ${ }^{9}$ That study revealed utilization improvements among children from all income groups, including lowincome children. Findings from studies analyzing CHIP's impact on US children's dental service utilization have been mixed. ${ }^{10-12}$ Studies repeatedly document marked racial/ethnic disparities in children receiving dental care. ${ }^{13-17} \mathrm{~A}$ dental use trends analysis between 1977 and 1996 using Medical Expenditure Panel Survey (MEPS) data revealed narrowing dental use rate gaps between white and nonwhite adults and children, though gaps in number of dental visits between white and nonwhite users of dental services persisted. ${ }^{18}$ These studies focused on single time points or relatively brief periods and lacked a historical policy perspective to gain insight into whether these utilization patterns changed over time.

The impetus for this study was the release of previously unavailable historic National Health Interview Survey (NHIS) data predating the advent of Great Society programs, including Medicaid. We analyzed and compared trends in dental utilization rates among African American and white US children, by using 1964 as the study baseline and 2010 as the study end point. Intermediate data points were selected based on available NHIS dental visit data.

Our study aims were to (1) examine whether dental utilization rates among African American and white US children changed significantly from 1964 to 2010 ; (2) determine whether historic African American/white disparities in children receiving dental care changed during this period; and (3) by using richer data available in the 1989, 1999, and 2010 NHIS, to further analyze African American/white disparities in children receiving dental care and assess if disparities remain, after accounting for sociodemographic variables.

\section{METHODS}

\section{Data Source}

We obtained data on race and dental care utilization for children aged 2 to 17 years from the 1964, 1976, 1989, 1999, and 2010 NHIS. The NHIS is a large-scale household interview survey that provides national estimates of demographic characteristics, health status and health care use, and access for the civilian noninstitutionalized US population. ${ }^{19}$ The sampling plan is a multistage probability design, redesigned after every decennial census. Since 1985, AfricanAmerican households have been oversampled. Data are collected by household interview with parents typically serving as respondents for children. The NHIS sample size has varied over the years. Details on NHIS are available elsewhere. ${ }^{19}$

\section{Dependent Variables}

Our main dependent variables were as follows: (1) child's receipt of a dental visit in the previous 12 months and (2) child's history of never having had a dental visit. These variables were derived from an NHIS question about the length of time since the child's last dental visit. Although the conceptual basis for questions on time since last dental visit has remained unchanged, 
the questionnaire wording has varied somewhat over time. The NHIS questions used over the years to categorize time since last dental visit are presented in Appendix 1. As per the National Center for Health Statistics health disparities guidelines, prevalences are reported as lack of a dental visit in the stipulated time period. ${ }^{20}$

\section{Independent Variables}

The primary independent variable was race, categorized as African American/ white. We focused on African American and white children because these 2 race categories were available consistently in the NHIS for the study period. The NHIS assessed race differently over the study period. From the first NHIS in 1957 through 1981, a child's race was recorded based on the parent's reported race or the interviewer's observation, probing verbally only when the race could not be determined. ${ }^{21}$ Hispanic origin was not recorded. Since 1982, the NHIS redesign required that all household members were asked race and Hispanic origin questions. The NHIS questions used over the years to categorize race are presented in Appendix 2. We conducted additional analyses by using the 1989,1999 , and 2010 NHIS data because more comprehensive data on Medicaid coverage and other sociodemographic variables were available.

\section{Multivariable Adjustment Variables}

We relied upon the Aday and Andersen 22 model to identify variables from 1989 , 1999, and 2010 NHIS data that were used for multivariable analyses. These variables included child age (coded 24, 5-11, and 12-17 years), gender, child overall health status (categorized as excellent/very good versus good/fair/ poor, due to the skewed distribution), functional limitation (limited versus not limited), child health insurance status (public versus private insurance), parent educational level ( $<$ high school, high school, or $\geq$ some college), family structure (2 versus single parent), region of residence (Northeast, Midwest, South, and West), and family income as a percent of the federal poverty level (FPL) adjusted for family size. For example, the FPL for a family of 4 in 2010 was $\$ 22050 .{ }^{23}$ This variable was coded as $<100 \%, 100 \%$ to $199 \%$, and $>200 \%$.

\section{Statistical Analysis}

The results for study aims 1 and 2 are presented in bivariable form by using charts and tables. Estimates presented were weighted by using the inverse of the sampling probability, adjusted for nonresponse. Sample prevalences (percentages) and associated confidence intervals (Cls) were estimated accounting for the complex NHIS sample design. We age-standardized estimates to the 2000 US Census. We used $\chi^{2}$ tests for linear trends to assess the changes in prevalence rates for both dependent variables from 1964 to 2010. Sample survey $\chi^{2}$ tests compared African American to white prevalences by year. We examined differences in dental utilization outcomes from 1989 to 2010 for all children by insurance and FPL status, to assess if improvements were concentrated among publicly insured children and poor children.

For aim 3, we conducted multivariable Iogistic regression analyses for 1989, 1999, and 2010 separately, to examine if bivariable relationships between African American/white racial categories and dependent variables (child receiving dental visits in the previous 12 months [none vs $\geq 1$ visit] and history of never versus ever having a dental visit) significantly differed, adjusting for sociodemographic covariates. Finally, we employed the Peters-Belson (PB) approach, which has previously been applied in wage discrimination ${ }^{24,25}$ and public health studies ${ }^{26,27}$ to quantify and characterize disparities between groups. The PB approach uses regression techniques to partition observed disparities into a component explained by covariates in the regression model ("explained disparity") and a remaining unexplained component ("unexplained disparity"). ${ }^{27}$ We accounted for the NHIS complex sample design and performed all analyses by using software (SAS version 9.2; SAS Institute, Inc, Cary, NC; SAScallable SUDAAN 10; Research Triangle International, Research Triangle Park, $\mathrm{NC})$.

\section{RESULTS}

\section{Racial Disparities: 1964-2010}

Sample sizes varied from 42973 in 1964 to 8647 in 2010. Overall, the percentage of African American and white US children without a dental visit in the previous 12 months declined significantly $(P<.01)$ from $52.4 \%$ in 1964 to $21.7 \%$ in 2010 , whereas the percentage of children who had never had a dental visit declined significantly $(P<.01)$ from $33.6 \%$ to $10.6 \%$ (Table 1). During the same period, for children lacking a dental visit in the previous 12 months, the pronounced African American/white disparities in prevalence, whereas large and statistically significant in 1964, attenuated and became nonsignificant by 2010 (Fig 1). Similarly, racial differences in prevalence of never seeing a dentist in 1964 diminished over time, becoming statistically nonsignificant by 2010 (Fig 2). Approximately $22 \%$ of the children in each racial group still lacked an annual dental visit in 2010.

\section{Insurance and Poverty: 1989-2010}

Given the large-scale expansions of public insurance programs directed at lower income families, we examined changes in dental utilization by insurance and poverty status. As seen in Table 2, the prevalence of children lacking dental visits (shown by insurance and poverty status) decreased from 1989 to 2010. However, changes 
TABLE 1 Total Prevalence of Lack of Dental Visits for African American and White Children in the United States, 1964-2010

\begin{tabular}{|c|c|c|c|}
\hline Year & $\begin{array}{l}\text { Sample } \\
\text { Size }\end{array}$ & $\begin{array}{c}\text { US Children (African American and White) } \\
\text { Aged 2-17 y Without a Dental Visit in } \\
\text { the Previous } 12 \mathrm{mo}^{\mathrm{a}}\end{array}$ & $\begin{array}{l}\text { US Children (African American and White) } \\
\text { Aged 2-17 y Who Never Had a Dental Visit }\end{array}$ \\
\hline & & $\begin{array}{l}\text { Total Weighted Prevalence in } \\
\qquad \%^{\mathrm{b}}(95 \% \mathrm{CI})\end{array}$ & $\begin{array}{l}\text { Total Weighted Prevalence in } \\
\qquad \%^{\mathrm{b}}(95 \% \mathrm{Cl})\end{array}$ \\
\hline 1964 & 42973 & $52.4(51.2-53.7)$ & $33.6(32.5-34.7)$ \\
\hline 1976 & 32296 & $43.9(42.7-45.1)$ & $21.1(20.3-21.9)$ \\
\hline 1989 & 26998 & $35.5(34.2-36.7)$ & $18.0(17.1-18.9)$ \\
\hline 1999 & 11126 & $28.4(27.2-29.6)$ & $14.5(13.6-15.3)$ \\
\hline 2010 & 8647 & $21.7(20.4-22.9)$ & $10.6(9.7-11.5)$ \\
\hline
\end{tabular}

a $P$ value for $\chi^{2}$ test of linear trend from 1964 to 2010 is $<.01$.

b Estimates are age-standardized to the 2000 US Census. were greater among children who were publicly insured (versus privately insured), as well as children who were poor or near-poor (compared with nonpoor children). Of note, the percentage of African American children with public insurance coverage increased from $31.4 \%$ to $62.8 \%$ from 1989 to 2010 , whereas for white children, rates increased from $7.6 \%$ to $35.1 \%$.

\section{Multivariable Analyses: 1989-2010}

Multivariable analyses of 1989 data indicate that compared with their white peers, African American children had higher odds of lacking a dental visit in the previous 12 months (odds ratio [OR]: 2.07 [95\% Cl: 1.81-2.31]; adjusted OR [a0R]: 1.47 [95\% Cl: 1.23-1.76]) (Table 3). However, by 2010, this racial difference became nonsignificant (OR: 1.06
[0.87-1.29]; a0R: 0.90 [0.71-1.16]). Racial differences for a history of never having had a dental visit were also nonsignificant in 2010 (OR: 0.85 [0.631.13]; a0R: 0.74 [0.49-1.10]) (Table 3). The PB analyses characterize African American/white differences in receiving a dental visit in the last 12 months, by quantifying the percent of the racial gap in each year explained by model covariates. In 1989, differences in the public/private insurance distribution between African American children and their white peers explained $23.2 \%$ of observed disparities (data not shown). When insurance and a poverty status variable were included in the model, $47.7 \%$ of the observed disparities were explained. In 1999, $58.9 \%$ of the observed disparities were explained by insurance only, whereas both insurance and poverty

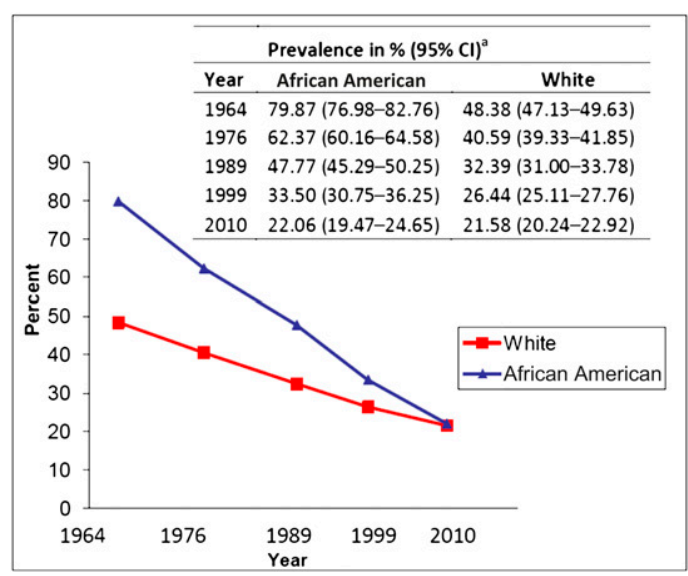

FIGURE 1

Prevalence (weighted) without a dental visit in the previous 12 months for US children 2 to 17 years of age, by race, 1964-2010. ${ }^{\text {a }}$ Estimates are age-standardized to the 2000 US Census. status explained $90.3 \%$ of the observed disparities. No PB analyses were conducted by using 2010 data because there were no significant African American/ white utilization rate differences.

\section{DISCUSSION}

This is the first study to take nearly a half-century perspective on changes in children's use and disparities in dental care, beginning before the implementation of Medicaid and other Great Society programs. For the study period spanning 1964-2010, we demonstrate significant improvements in children's receipt of dental care overall, as well as a dramatic narrowing in African American/white disparities. For the more recent time period of 1989-2010, our results indicate that utilization improvements were greater among publicly insured children, as well as poor and near-poor children. The implementation and expansion of the federal programs over time have had a cumulative and growing impact. The gradual but progressive program expansions and the high enrollment rates of African American children may have contributed to progressive reductions in dental access disparities over time. The programs disproportionately benefited African American children largely because more were eligible for these programs. African American children, although being only approximately half as likely as their white counterparts to have private health insurance in 2007, were almost 3 times as likely to have public coverage, primarily Medicaid or CHIP.16 The achievement of near African American/white equality in dental visits by 2010 was confirmed by using multivariable analyses adjusting for other factors associated with race, such as parental educational attainment.

Importantly, however, not all data sources reveal similar results. A MEPS Web site data query indicated in 2007 


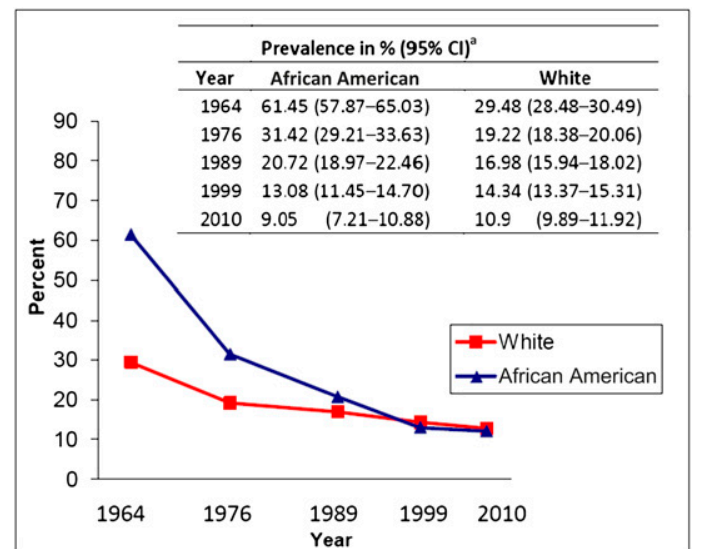

FIGURE 2

Prevalence (weighted) with a history of never having had a dental visit for US children 2 to 17 years of age, by race, $1964-2010$. $^{\text {a }}$ Estimates are age-standardized to the 2000 US Census. that non-Hispanic African American children aged 2 to 17 years were more likely than their white peers to lack dental visits in the past year $(58 \%$ vs 41\%). ${ }^{28}$ However, the MEPS-based dental visit rates differ considerably from other national and state surveys, not just the NHIS. A 2007 National Survey of Children's Health Web site data query indicates no significant differences in non-Hispanic African American and white children ages 1 to 17 years without a preventive dental visit in the past year ( $21.7 \%$ vs $19.1 \%$, respectively). ${ }^{29}$ Data from the 2007 California Health Interview Survey also reveal no statistically significant differences in the proportion of non-Hispanic African American and white children without a dental visit in the past year $(17.1 \%$ vs $12.1 \%$, respectively). ${ }^{30}$ It is unclear why MEPS dental visit rates differ so greatly from other surveys, though it may stem partly from differences in survey methodologies. One study comparing dental utilization estimates across 3 nationally representative surveys noted MEPS estimates were consistently lower than the NHIS or NHANES. ${ }^{31}$ The authors attributed these differences to design issues and differential approaches to dental visit assessments. Edelstein, ${ }^{17}$ in discussing the discrepancies, suggests the MEPS may understate visit rates, whereas the NHIS might overstate visit rates. The NHIS has the advantage of providing nationally representative dental care use estimates from 1957 (electronic
TABLE 2 Rates of Lack of Dental Visits for African American and White Children by Insurance and Poverty Status in 1989, 1999, and 2010

\begin{tabular}{lccccc}
\hline & $1989, \%$ & $1999, \%$ & $2010, \%$ & 1999-1989 Change & 2010-1999 Change \\
\hline Last dental visit $>12$ mo $^{\text {a’b }}$ & & & & & -13.6 \\
$\quad$ Public insurance & 44.6 & 36.3 & 22.7 & -8.3 & -4.6 \\
$\quad$ Private insurance & 29.4 & 21.7 & 17.1 & -7.7 & -14.2 \\
$\quad$ Poor & 53.1 & 41.8 & 27.6 & -11.3 & -12.8 \\
$\quad$ Near poor & 45.3 & 39.3 & 26.5 & -6.0 & -3.6 \\
$\quad$ Nonpoor & 24.4 & 20.6 & 17.0 & -3.8 & -7.6 \\
Never had a dental visita.b & & & & & -2.7 \\
$\quad$ Public insurance & 21.8 & 19.3 & 11.7 & -2.5 & -6.6 \\
Private insurance & 15.1 & 12.1 & 9.4 & -3.0 & -4.9 \\
Poor & 26.2 & 19.1 & 12.5 & -7.1 & -2.5 \\
$\quad$ Near poor & 22.2 & 16.8 & 11.9 & -5.4 & \\
Nonpoor & 12.7 & 11.7 & 9.2 & -1.0 & \\
\hline
\end{tabular}

a Uninsured children are not included.

b Poor, family income $<100 \%$ of FPL; near poor, family income $100 \%$ to $199 \%$ of FPL; Nonpoor, family income $\geq 200 \%$ of FPL. data are available beginning with 1964) permitting analysis of health care utilization trends over time, including before Medicaid.

Even with marked decreases in African American/white disparities in children's dental visits demonstrated in this study, other data reveal persistent and substantial disparities in children's oral health status. ${ }^{32}$ Examination data from the 2001-2004 NHANES reveal that African American children aged 2 to 5 years were $67 \%$ more likely to have untreated dental caries than their white counterparts, whereas African American children and adolescents ages 6 to 19 years were $45 \%$ more likely to have untreated caries. ${ }^{33}$ Over the past 20 years, African American children have experienced substantial reductions in untreated dental caries rates. However, untreated caries continues to be far more prevalent among African American children, with the racial gap actually increasing somewhat for the younger age group. ${ }^{33}$ The persistent gap in oral health status by race, despite improvements in dental utilization patterns, may be attributable to various factors. Dental care is 1 of many contributors to children's oral health, so for their oral health status to improve, these additional factors must also be addressed. Numerous factors at multiple levels (individual, family, and community) also influence oral health. ${ }^{13,34-37}$ For example, communities differ in socioeconomic disadvantage, culture, cohesion, or access to resources (eg, fluoridated water, dentists, and healthy foods) they afford their residents. Such contextual differences may help explain differences in oral health and dental utilization between races. Tellez et al ${ }^{38}$ demonstrated that the number of neighborhood grocery stores was associated with caries levels among African American caregivers in Detroit. Further, the quality (technical and interpersonal), frequency, and type of dental care (especially extent of preventive 
TABLE 3 Crude and aORs for Lack of Dental Visits Among US Children by Race in 1989, 1999, and 2010

\begin{tabular}{|c|c|c|c|c|c|c|}
\hline & \multicolumn{6}{|c|}{ History of No Dental Visit Within the Last $12 \mathrm{mo}, 0 \mathrm{Rs}$ (95\% Cls) } \\
\hline & \multicolumn{2}{|c|}{1989} & \multicolumn{2}{|c|}{1999} & \multicolumn{2}{|c|}{2010} \\
\hline & Unadjusted & Adjusteda & Unadjusted & Adjusteda & Unadjusted & Adjusteda \\
\hline \multicolumn{7}{|l|}{ Child race/ethnicity } \\
\hline Non-Hispanic whiteb & 1.0 & 1.0 & 1.0 & 1.0 & 1.0 & 1.0 \\
\hline \multirow[t]{3}{*}{ Non-Hispanic black } & $2.07(1.81-2.31)$ & $1.47(1.23-1.76)$ & $1.42(1.18-1.71)$ & $1.03(0.80-1.32)$ & $1.06(0.87-1.29)$ & $0.90(0.71-1.16)$ \\
\hline & \multicolumn{6}{|c|}{ History of Never Having Had a Dental Visit, ORs (95\% Cls) } \\
\hline & Unadjusted & Adjusteda & Unadjusted & Adjusteda & Unadjusted & Adjusteda \\
\hline \multicolumn{7}{|l|}{ Child race/ethnicity } \\
\hline Non-Hispanic whiteb & 1.0 & 1.0 & 1.0 & 1.0 & 1.0 & 1.0 \\
\hline Non-Hispanic black & $1.32(1.10-1.60)$ & $1.42(1.24-1.63)$ & $0.91(0.73-1.12)$ & $0.60(0.42-0.85)$ & $0.85(0.63-1.13)$ & $0.74(0.49-1.10)$ \\
\hline
\end{tabular}

services) African American and white children receive may differ. ${ }^{39,40}$ Minority children have more symptom-related dental visits than their peers ${ }^{17}$ and have longer intervals between visits. ${ }^{41}$ In some states, African American Medicaidenrolled children receiving dental care were less likely than their white peers to receive comprehensive dental services, including restorative and surgical treatment. ${ }^{42}$ These same children were also more likely to be treated by dental providers who mostly provide diagnostic and preventive dental services. ${ }^{42} \mathrm{Al}$ though preventive dental care can be effective in reducing dental disease, ${ }^{43,44}$ some children still require restorative or surgical dental treatment. Access to preventive dental care is associated with receiving comprehensive dental treatment, 45 but a significant percentage of Medicaid-enrolled children who receive preventive dental care still have unmet restorative dental treatment needs. ${ }^{46,47}$

These findings suggest that additional measures are needed to ensure children receive appropriate and comprehensive dental care commensurate with their needs. Research suggests health disparities can be impacted through providing prevention oriented medical care that addresses social determinants of health within the context of clinical care delivery. ${ }^{48,49}$ Such efforts could be especially helpful in reducing racial disparities given that a disproportionate percentage of African American children are enrolled in Medicaid.

Under Medicaid's EPSDT program, states must provide dental screening, diagnostic, preventive, and treatment services for all enrolled children, even if those services are not normally covered under the state's Medicaid program. However, these federal regulations are inconsistently enforced. Indeed, advocates in several states have resorted to class action litigation to enforce EPSDT regulations, but these efforts are piecemeal, often dragging on for years in the courts without definitive resolution.*

Despite these shortcomings, the EPSDT program has had some modest impact. The Centers for Medicare and Medicaid Services reports that between 2000 and 2009, children's access to dental care in Medicaid/CHIP improved, although improvements varied across states. ${ }^{50}$ The significant increase in numbers of children enrolled in Medicaid/CHIP and associated enhancements in dental provider capacity could have facilitated improved access to dental care overall. The Centers for Medicare and Medicaid Services recently developed oral health

*Current examples include Tennessee and Texas. goals to improve preventive dental service usage for children in Medicaid/ CHIP programs. In addition to these efforts, a stronger federal hand requiring that states adhere to EPSDT regulations could have pronounced benefits in improving health care delivery and ultimately, health care outcomes. The federal and state governments could also work together to establish guidelines and policies to ensure children identified with untreated oral health problems during dental screenings are linked to dental providers able to offer timely comprehensive treatment.

This study has several limitations. The NHIS relies on parental self-reported dental visits and does not verify actual receipt of dental care. Although studies demonstrated the validity of self-reported dental visits, ${ }^{51,52}$ our findings could be subject to reporting inaccuracy. We could not differentiate dental visit types because the NHIS does not distinguish among emergency, restorative, and preventive dental visits. Although the wording of the NHIS dental visit questions changed slightly over time, we have no reason to expect that these changes would affect responses for white and African American children differentially. Although the NHIS design minimizes nonresponse bias, differential measurement error 
by race remains a possibility. Changes in how race was measured (observercoded versus self-reported) and categorized in the NHIS over time could also have affected our results. Another important limitation is the change in the conceptualization of race in US health research over the years.53,54 Race is now more widely considered a social construct based on phenotype rather than a biological construct. ${ }^{55-57}$

Results from our multivariable models could also be biased. Kaufman et al58 caution about multivariable analyses that make racial/ethnic comparisons because potential confounders are associated with both the outcome variables and the group indicators. Further, multivariable models that adjust for individual- and family-level socioeconomic status (SES) measures do not fully account for various unmeasured characteristics differing between racial groups. ${ }^{49}$ Because of factors such as measurement error, SES categorization, variable aggregation, and nonequivalent SES measures across race, residual confounding is a concern. ${ }^{58}$ Finally, we do not demonstrate a causal relationship between public health insurance expansions and reductions in racial disparities over the study period. Other contemporaneous events that we were unable to measure could have played contributory roles. Therefore, our findings should be interpreted with caution. Nonetheless, the results provide a template for continued disparity monitoring, as well as a baseline for assessing the impact of future changes in public programs and private health insurance. Findings can also inform the development of policies designed to improve access to care and eliminate disparities among other racial/ethnic groups, including Hispanic children.

\section{CONCLUSIONS}

This study documents a narrowing ofthe gap in African American/white disparities in children's receipt of dental care. Yet, much more needs to be done before persistent racial disparities in children's oral health status are eliminated.

\section{ACKNOWLEDGMENTS}

We thank Drs Milton Kotelchuck and Sowmya R. Rao for their support and contributions to this study.

\section{REFERENCES}

1. Newacheck PW, Hughes DC, Hung YY, Wong S, Stoddard JJ. The unmet health needs of America's children. Pediatrics. 2000;105 (4 pt 2):989-997

2. United States code. Title 42, Subchapter XIX: Grants to states for medical assistance programs. Legal Information Institute. Available at: www.law.cornell.edu/uscode/42/usc sup_01_42_10_7_20_XIX.html. Accessed March 22, 2012

3. Moore J, Smith D. Legislating Medicaid considering Medicaid and its origin. Health Care Financ Rev. 2005-2006;27 (2):45-52

4. United States Code: Title 42. Chapter 7. Subchapter XIX, $\S 1396 d(r)$, Early and Periodic Screening, Diagnostic, and Treatment Services. Available at: http://www.law.cornell. edu/uscode/text/42/1396d. Accessed March 22, 2012

5. US Government Printing Office. Balanced Budget Act of 1997. Publication no. 105-033. Available at: http://frwebgate.access.gpo. gov/cgi-bin/getdoc.coi? dbname=105_cong_ public_laws\&docid=f:publ33.105. Accessed March 22, 2012

6. Kennedy EM. The role of the federal government in eliminating health disparities. Health Aff (Millwood). 2005;24(2):452-458

7. Children's Health Insurance Program Reauthorization Act of 2009 (CHIPRA). Kaiser Commission on Medicaid and the Uninsured. Key facts. February 2009. Available at: www.kff. org/medicaid/upload/7863.pdf. Accessed March 22, 2012

8. Edelstein BL, Samad F, Mullin L, Booth M. Oral health provisions in U.S. health care reform. J Am Dent Assoc. 2010;141(12): 1471-1479

9. Hughes DC, Duderstadt KG, Soobader MP, Newacheck PW. Disparities in children's use of oral health services. Public Health Rep. 2005;120(4):455-462

10. Duderstadt KG, Hughes DC, Soobader MJ, Newacheck PW. The impact of public insurance expansions on children's access and use of care. Pediatrics. 2006;118(4): 1676-1682

11. Wang $H$, Norton E, Rozier RG. Effects of the State Children's Health Insurance Program on access to dental care and use of dental services. Health Serv Res. 2007;42(4):15441563

12. Edelstein B, Schneider D, Laughlin R. SCHIP dental performance over the first 10 years: findings from the literature and a new ADA survey: executive summary. Chicago, IL: American Dental Association; 2008. Available at: Http://www.ada.org/sections/advocacy/ pdfs/071120_SCHIP_Executive_Summary.pdf. Accessed March 22, 2012

13. Dietrich T, Culler C, Garcia RI, Henshaw MM. Racial and ethnic disparities in children's oral health: the National Survey of Children's Health. J Am Dent Assoc. 2008;139(11): 1507-1517
14. Mouradian WE, Wehr E, Crall JJ. Disparities in children's oral health and access to dental care. JAMA. 2000;284(20):2625-2631

15. Lewis CW, Johnston BD, Linsenmeyar KA, Williams A, Mouradian W. Preventive dental care for children in the United States: a national perspective. Pediatrics. 2007;119 (3). Available at: www.pediatrics.org/cgi/ content/full/119/3/e544

16. Flores G, Tomany-Korman SC. Racial and ethnic disparities in medical and dental health, access to care, and use of services in US children. Pediatrics. 2008;121(2). Available at: www.pediatrics.org/coi/content/full/ 121/2/e286

17. Edelstein BL. Disparities in oral health and access to care: findings of national surveys. Ambul Pediatr. 2002;2(suppl 2):141-147

18. Manski RJ, Moeller JF, Maas WR. Dental services. An analysis of utilization over 20 years. J Am Dent Assoc. 2001;132(5):655-664

19. Centers for Disease Control and Prevention. NHIS: questionnaires, datasets, and related documentation. Available at: www. cdc.gov/nchs/nhis/nhis_questionnaires.htm. Accessed March 22, 2012

20. Keppel K, Pamuk E, Lynch J, et al. Methodological issues in measuring health disparities. Vital Health Stat 2. 2005;(141):1-16

21. Centers for Disease Control and Prevention. NHIS: race and Hispanic origin information. Historical context. Available at: http://www. 
cdc.gov/nchs/nhis/rhoi/rhoi_history.htm. Accessed March 22, 2012

22. Aday LA, Andersen R. A framework for the study of access to medical care. Health Serv Res. 1974;9(3):208-220

23. Assistant Secretary for Planning and Evaluation, US Department of Health \& Human Services. The 2010 health and human services poverty guidelines. Available at: http:// aspe.hhs.gov/poverty/10poverty.shtml. Accessed March 22, 2012

24. Oaxaca R. Male-female wage differentials in urban labor markets. Int Econ Rev. 1973; 14:693-709

25. Blinder AS. Wage discrimination: reduced form and structural estimates. J Hum Resources. 1973;8:436-455

26. Graubard BI, Sowmya Rao R, Gastwirth JL. Using the Peters-Belson method to measure health care disparities from complex survey data. Stat Med. 2005;24(17):26592668

27. Rao RS, Graubard BI, Breen N, Gastwirth JL. Understanding the factors underlying disparities in cancer screening rates using the Peters-Belson approach: results from the 1998 National Health Interview Survey. Med Care. 2004;42(8):789-800

28. Medical Expenditure Panel Survey, Agency for Healthcare Research and Quality, US Department of Health \& Human Services. MEPSnet/HC query. Available at: http://meps. ahrq.gov/mepsweb/data_stats/MEPSnetHC. jsp. Accessed March 22, 2012

29. National Survey of Children's Health. Data query results. Available at: http://nschdata.org/ DataQuery/DataQueryResults.aspx. Accessed March 22, 2012

30. California Health Interview Survey. AskCHIS. Data query results. Available at: www. askchis.com/main/default.asp. Accessed March 22, 2012

31. Macek MD, Manski RJ, Vargas CM, Moeller JF. Comparing oral health care utilization estimates in the United States across three nationally representative surveys. Health Serv Res. 2002;37(2):499-521

32. Edelstein BL, Chinn CH. Update on disparities in oral health and access to dental care for America's children. Acad Pediatr. 2009;9(6):415-419

33. National Center for Health Statistics. Health, United States, 2009. Updated in 2010. Hyattsville, MD: National Center for Health Statistics. Available at: www.cdc.gov/nchs/ data/hus/hus09.pdf. Accessed March 22, 2012

34. Chu M, Sweis LE, Guay AH, Manski RJ. The dental care of U.S. children: access, use and referrals by nondentist providers, 2003. J Am Dent Assoc. 2007;138(10):1324-1331
35. Grembowski D, Spiekerman C, Milgrom P. Linking mother and child access to dental care. Pediatrics. 2008;122(4). Available at: www.pediatrics.org/cgi/content/full/122/4/ e805

36. Turrell G, Sanders AE, Slade GD, Spencer AJ, Marcenes W. The independent contribution of neighborhood disadvantage and individual-level socioeconomic position to self-reported oral health: a multilevel analysis. Community Dent Oral Epidemiol. 2007;35(3):195-206

37. Fisher-Owens SA, Gansky SA, Platt LJ, et al. Influences on children's oral health: a conceptual model. Pediatrics. 2007;120(3). Available at: www.pediatrics.org/cgi/content/full/ 120/3/e510

38. Tellez M, Sohn W, Burt BA, Ismail Al. Assessment of the relationship between neighborhood characteristics and dental caries severity among low-income AfricanAmericans: a multilevel approach. J Public Health Dent. 2006:66(1):30-36

39. Kelly SE, Binkley CJ, Neace WP, Gale BS. Barriers to care-seeking for children's oral health among low-income caregivers. Am J Public Health. 2005;95(8):1345-1351

40. Mofidi M, Rozier RG, King RS. Problems with access to dental care for Medicaid-insured children: what caregivers think. Am J Public Health. 2002;92(1):53-58

41. Pourat N, Finocchio L. Racial and ethnic disparities in dental care for publicly insured children. Health Aff (Millwood). 2010; 29(7):1356-1363

42. Taichman LS, Sohn W, Lim S, Eklund S, Ismail A. Assessing patterns of restorative and preventive care among children enrolled in Medicaid, by type of dental care provider. J Am Dent Assoc. 2009;140(7):886-894

43. Ahovuo-Saloranta A, Hiiri A, Nordblad A, Worthington $\mathrm{H}$, Makela M. Pit and fissure sealants for preventing dental decay in the permanent teeth of children and adolescents. Cochrane Database Syst Rev. 2004; (3):CD001830

44. Savage MF, Lee JY, Kotch JB, Vann WF Jr. Early preventive dental visits: effects on subsequent utilization and costs. Pediatrics. 2004;114(4). Available at: www.pediatrics. org/cgi/content/full/114/4/e418

45. Lee MA, Horan SA. Children's access to dental care in Connecticut's Medicaid managed care program. Matern Child Health J. 2001;5(1):43-51

46. Robison VA, Rozier RG, Weintraub JA. A Iongitudinal study of schoolchildren's experience in the North Carolina Dental Medicaid Program, 1984 through 1992. Am J Public Health. 1998;88(11):1669-1673
47. VanLandeghem K, Bronstein J, Brach C Children's Dental Care Access in Medicaid: The Role of Medical Care Use and Dentist Participation. CHIRI Issue Brief 2. AHRQ Publication 03-0032. Rockville, MD Agency for Healthcare Research and Quality; 2003

48. Williams DR, Costa MV, Odunlami AO Mohammed SA. Moving upstream: how interventions that address the social determinants of health can improve health and reduce disparities. J Public Health Manag Pract. 2008;14(suppl):S8-S17

49. Williams DR, Mohammed SA, Leavell J, Collins C. Race, socioeconomic status, and health: complexities, ongoing challenges, and research opportunities. Ann $N$ Y Acad Sci. 2010;1186:69-101

50. Health and Human Services Secretary. Kathleen Sebelius. The Department of Health and Human Services Children's Health Insurance Program Reauthorization Act 2011 Annual Report on the Quality of Care for Children in Medicaid and CHIP. September 2011. Available at: www.medicaid.gov/ Medicaid-CHIP-Program-Information/ByTopics/Quality-of-Care/Downloads/2011_ StateReporttoCongress.pdf. Accessed March 22, 2012

51. Gilbert GH, Rose JS, Shelton BJ. A prospective study of the validity of self-reported use of specific types of dental services. Public Health Rep. 2003;118(1):18-26

52. Gilbert GH, Rose JS, Shelton BJ. A prospective study of the validity of data on self-reported dental visits. Community Dent Oral Epidemiol. 2002;30(5):352-362

53. Sheldon TA, Parker H. Race and ethnicity in health research. J Public Health Med. 1992 14(2): 104-110

54. Williams DR. The concept of race in health services research: 1966 to 1990. Health Serv Res. 1994;29(3):261-274

55. Williams DR, Lavizzo-Mourey R, Warren RC. The concept of race and health status in America. Public Health Rep. 1994;109(1) 26-41

56. Jones CP. Invited commentary: "race," racism, and the practice of epidemiology. Am J Epidemiol. 2001;154(4):299-304, discussion 305-306

57. Ford ME, Kelly PA. Conceptualizing and categorizing race and ethnicity in health services research. Health Serv Res. 2005;40 (5 pt 2):1658-1675

58. Kaufman JS, Cooper RS, McGee DL. Socioeconomic status and health in blacks and whites: the problem of residual confounding and the resiliency of race. Epidemiology. 1997;8(6):621-628 
APPENDIX 1 NHIS Dental Visit Questions: 1964, 1976, 1989, 1999, and 2010

\begin{tabular}{|c|c|}
\hline & $\begin{array}{c}\text { NHIS Data } \\
\text { Year }\end{array}$ \\
\hline $\begin{array}{l}\text { How long has it been since you went } \\
\text { to a dentist? (Responses: _ mo; } \\
\text { _y; }<1 \mathrm{mo} \text {, never) }\end{array}$ & 1964 \\
\hline $\begin{array}{l}\text { About how long has it been since } X \\
\text { last went to a dentist? (Responses: } \\
2 \text { wk, }>2 \text { wk- } 6 \text { mo; }>6 \text { mo-1 y; } \\
1 \text { y, 2-4 y; } 5+\text { y; never) }\end{array}$ & 1976 \\
\hline $\begin{array}{l}\text { About how long has it been since } X \\
\text { last went to a dentist? (Responses: } \\
2 \text { wk, }>2 \text { wk }<6 \text { mo; } 6 \text { mo-1 y; } \\
1 \text { y, }<2 \text { y; } 2 \text { y, }<5 \text { y; } \geq 5 \text { y; never) }\end{array}$ & 1989 \\
\hline $\begin{array}{l}\text { About how long has it been since } X \\
\text { last saw or talked to a dentist? } \\
\text { Include all types of dentists, such } \\
\text { as orthodontists, oral surgeons, } \\
\text { and all other dental specialists, } \\
\text { as well as dental hygienists. } \\
\text { (Responses: } \leq 6 \text { mo; }>6 \text { mo but } \\
\text { not }>1 \mathrm{y} ;>1 \mathrm{y} \text {, but not }>2 \mathrm{y} ;>2 \mathrm{y} \text {, } \\
\text { but not }>5 \mathrm{y} ;>5 \mathrm{y} \text {; never; refused, } \\
\text { don't know) }\end{array}$ & 1999 \\
\hline $\begin{array}{l}\text { About how long has it been since } X \\
\text { last saw a dentist? Include all types } \\
\text { of dentists, such as orthodontists, } \\
\text { oral surgeons, and all other dental } \\
\text { specialists, as well as dental } \\
\text { hygienists. (Responses: } \leq 6 \mathrm{mo} \text {; } \\
>6 \text { mo but not }>1 \mathrm{y} ;>1 \mathrm{y} \text {, but not } \\
>2 \mathrm{y} ;>2 \mathrm{y} \text {, but not }>5 \mathrm{y} ;>5 \mathrm{y} \text {; } \\
\text { never; refused, don't know) }\end{array}$ & 2010 \\
\hline
\end{tabular}

$X$, sample child
APPENDIX 2 NHIS Racial Category Questions: 1964, 1976, 1989, 1999, and 2010

\begin{aligned} \hline NHIS \\ Data \\ Year \\ \hline\end{aligned}

Race: Check one box: white, negro,

1964

other

Race: Check one box: white, negro, 1976

other

1. What is the number of the group/ groups that represents $X$ race? (Or what is $X$ race?) (Responses: Aleut, Eskimo or American Indian; Asian or Pacific Islander; black; white; other)

2. Are any of those groups $X$ national origin or ancestry? (Or where did $X$ 's ancestors come from?)

(Responses: Puerto Rican, Cuban, Mexican, Mexican American, Chicano, other Latin American, other Spanish)

1. Does $X$ consider himself to be Hispanic or Latino? (origin, etc...). Yes/no.

2. Please pick the group that represents your Hispanic origin.

3. What race does $X$ consider himself to be? (Responses: white, black/ African American, Indian (American), Native Hawaiian, Guamanian, Samoan, other Pacific Islander, Asian Indian, Chinese, Filipino, Japanese, Korean, Vietnamese, other Asian, some other race)

$\mathrm{X}$, sample child. 